\title{
Association of Lutzomyia columbiana (Diptera: Psychodidae) with a Leishmaniasis Focus in Colombia Due to Species of the Leishmania mexicana Complex
}

\author{
James Montoya-lerma ${ }^{+}$, Horacio Cadena, Iris Segura, Bruno Luis Travi \\ Centro Intemacional de Entrenamiento e Investigaciones Médicas, CIDEIM, Apartado Aéreo 5390, Cali, \\ Colombia
}

In Colombia, Leishmania mexicana has a scattered geographical distribution and no sand fly vectors have been associated with its transmission. During the present study, the anthropophilic sand fly Lutzomyia columbiana was found to be the only species collected using diverse methods, in a small focus of Le. mexicana in the municipality of Samaniego, SW Colombia. Ecological data indicate that this sand fly species is present in both peri and intradomestic habitats, where it readily bites man. Further evidence comes from experimental itnfections of wild-caught Lu. columbiana with Le. mexicana after feeding on itnfected hamsters. Based on these results, it is suggested that this sand fly is the most likely vector in the study area, suggesting the existence of a previously unknown sand fly-parasite association.

Key words: leishmaniasis - Leishmania mexicana - Lutzomyia columbiana - experimental infection - Colombia

Leishmania (Leishmania) mexicana Biagi, one of the etiological agents of cutaneous leishmaniasis, occurs in the Americas in two well defined regions. The first covers areas of Mexico, Guatemala, Belize, and Honduras (Biagi et al. 1965, Disney 1968, Williams 1970, Porter et al. 1987), while the second is represented by scattered foci in the Colombian and Ecuadorian Andes (Rodríguez et al. 1985, Hashiguchi et al. 1991). Other variants of Le. mexicana have been isolated but poorly characterized in the United States, Dominican Republic, Panama and Venezuela (Grimaldi et al. 1989). The typical human clinical manifestation of $L e$. (Le.) mexicana infection is the simple cutaneous sore ("Chiciero's ulcer"), though chronic, destructive and painful or disseminated (anergic) lesions have been also recorded. In spite of its importance, relatively little is known about the transmission of Le. mexicana throughout its range, especially in

This work was supported by the U.S. National Institute of Allergy and Infectious Diseases, National Institutes of Health - Tropical Medicine Research Center (TMRC), Grant P50-A130603 and COLCIENCIAS, Grant 222904193-95.

${ }^{+}$Corresponding author. Present Address: Departamento de Biologia, Universidad del Valle, Apartado Adreo 25360, Cali-Colombia. Fax: (57) 23393243. E-mail: jamesmon@biologia.univalle.edu.co

Received 7 April 1998

Accepted 27 January 1999 the southern part. Biagi et al.(1965), Disney (1968) and Williams (1970) found that Lutzomyia olmeca olmeca (Diptera: Psychodidae) was the vector in endemic areas of Mexico and Belize, while Porter et al. (1987) recorded a natural infection of $L u$. ylephiletor in Guatemala. In these areas, small rodents (e.g. Ototylomys sp., Heteromys sp., Nyctomys sp. and Sigmodon sp.) were identified as reservoirs of the parasite (Disney 1968, Williams 1970, Lainson \& Shaw 1987). Recently, Hashiguchi et al. (1991) reported Lu. ayacuchensis (a species which is not related to the known vectors of Le. mexicana, i.e. Lu. ylephiletor and Lu. olmeca) as the most likely vector of this parasite in an Ecuadorian Andean village.

In Colombia, Le. mexicana presents a wide but patchy distribution covering three ecological zones of the Andes (Fig. 1) in the departments of Nariño, Risaralda and Santander, (Rodríguez et al. 1985, Corredor et al. 1990). The available epidemiological information has been gathered from clinical studies but no investigations on ecological or entomological aspects (particularly the incrimination of sand fly vectors) have been undertaken, so that the transmission cycle of Le. mexicana remains virtually unknown.

Occasional reports of human cases of cutaneous leishmaniasis (CL) with clinical characteristics indicating Le. mexicana infection from Samaniego, SW Colombia, prompted us to carry out the present study. The main objectives were to determine the composition of the sand fly fauna in Samaniego, to assess the vector capacity of $L u$. 


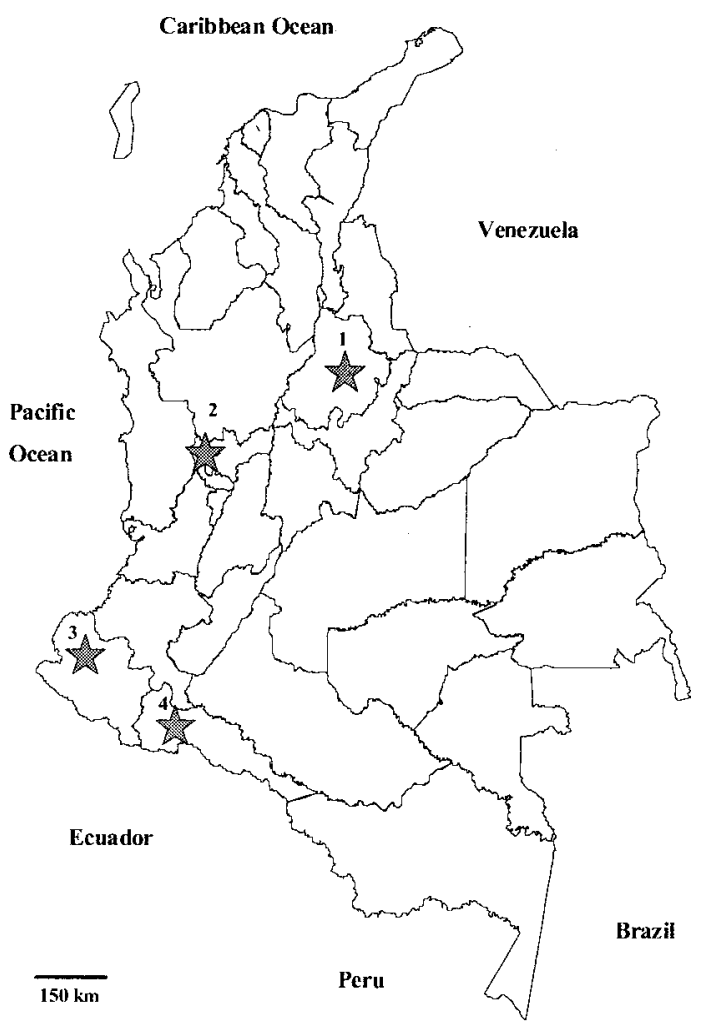

Fig. 1: geographic position of Colombia and location of the recorded Leishmania mexicana (Biagi) foci in the country: 1) Santander, 2) Risaralda, 3) Nariño, and 4) Putumayo.

columbiana (Ristorcelli \& Van-Ty) and to confirm by isozymes the taxonomical status of the isolates circulating in the area.

\section{MATERIALS AND METHODS}

The field study was carried out in La Mesa, located $15 \mathrm{~km}$ from Samaniego $\left(1^{\circ} 25^{\prime} \mathrm{N} ; 7^{\circ} 34^{\prime} \mathrm{W}\right)$. Ecologically, the zone may be considered as a highly disturbed, low montane dry forest (Holdridge 1967, cited by Bernal et al. 1989) at an elevation of approximately $1600 \mathrm{~m}$ above sea level. The annual average temperature, relative humidity and precipitation are $19.6^{\circ} \mathrm{C}, 81 \%$ and $1280 \mathrm{~mm}$, respectively (Instituto de Adecuación de Tierras y Recursos Hidrológicos, HIMAT 1993). Cultivation of coffee, plantain, maize, represent the main agricultural activities. Trees such as mango (Manguifera indica), orange (Citrus aurantium), guava (Psidium guajava), achiote (Bixaorellana sp.), guamo (Inga spp.) and African tulip (Spathodea campanulata beauvais) provide shade for the coffee plantations. Domestic animal reared include guinea pigs, rabbits and poultry, with crops and animal shelters often adjacent to human dwellings.
The houses are constructed of adobe and most have basic amenities such as outdoor latrines and electricity.

The parasite strain (MHOM/COL/85/1129) was isolated by aspirate culture from the cutaneous ulcer of a Samaniego patient. Half of the aspirate (0.1 ml PBS) was seeded in Senekjie's culture medium, while the remaining volume was inoculated in the snout of a Syrian hamster. The isolate was subsequently identified by isozymes (Saravia et al. 1985) using three World Health Organization reference strains as controls. Additionally, a Le. mexicana isolate obtained from a patient in Buenaventura (Department of Valle del Cauca), a non-endemic area for this parasite, was included in the analysis. All the parasite strains were propagated for four days at $27^{\circ} \mathrm{C}$ in Schneider's Drosophila medium (Gibco, Grand Island, NY) plus 10\% of inactivated bovine scrum and $1 \%$ penicillinstreptomycin solution (Gibco Lab.). Standard methods for isoenzymatic characterization were used (Saravia et al. 1985).

Three houses were selected for sand fly collections. Houses 1 and 2 were very close to each other and were inhabited by people recently diagnosed as having CL. House 3 was approximately $300 \mathrm{~m}$ from houses 1 and 2, and none of its residents had reported having CL. Sand fly collections were made inside houses and in the peridomicile (in plantations at 10-30 m from houses).

The species composition of the sand fly fauna, and its relative density, was estimated using sticky traps $(20 \times 30 \mathrm{~cm}$ sheets of paper impregnated with castor oil). These were distributed at different heights on the interior walls of houses 1 ( $n=10$ traps) and 3 ( $n=9$ traps); no traps were set up in house 2 . In addition, a total of 12,10 and 15 sticky traps were distributed in the peridomiciles of houses 1,2 and 3 , respectively. Traps were hung before dark (18:30 hr), left overnight and inspected the next morning (5:30 hr) during three consecutive days.

Human bait collections in the intra- and peridomestic habitats were carried out by two adult volunteers per house. They wore protective clothing against sand fly bites and caught sand flies alighting on them from 19 to $21 \mathrm{hr}$ using buccal aspirators. Collectors were rotated between houses on each of the three consecutive nights of sampling. Results were calculated as sand flies/man/ hour.

Sand fly attraction to hamsters and guinea pigs was assessed using Disney traps (Disney 1968). With this trap, sand flies attracted to animals are trapped on oiled surfaces surrounding the animal cage, before or after attempting to feed on the bait. Traps were set at dusk inside house 1 and peridomicile of houses 2 and 3. Disney traps were 
examined the following morning, all sand flies adhered to the oiled surfaces being removed, transported in saline solution to the laboratory and dissected the same day.

Attraction of sand flies by a combination of light and animal baits was determined using three CDC miniature traps (Service 1993) set up in the proximity of rabbit and guinea pig shelters. Traps were operated from 19 to $21 \mathrm{hr}$ inside house 3 and in the peridomicile of houses 1 and 2 .

An active search for diurnal resting places (i.e. crevices in the walls of houses, burrows, tree holes, tree trunks, and leaves) was carried out early in the morning during three days.

Female sand flies were individually dissected to look for natural infections in their digestive tracts, and identified according to Young and Duncan (1994). Blood meals from fed flies were identified by Elisa (Voller et al. 1980).

Experimental infections were carried out at the CIDEIM entomology laboratory in Cali, using two hamsters experimentally infected with $L e$. mexicana and wild-caught $L u$. columbiana from Jiguales, a village $40 \mathrm{~km}$ from Cali where $L e$. mexicana cases have never been reported.

Hamsters inoculated in the hind feet with approximately $1 \times 10^{6}$ cultured promastigotes from the stationary phase of growth were maintained under standard conditions. Flies were collected using a modified Shannon trap (Service 1993), transported to the laboratory, and fed the same night on chronic (8-14 months-old) leishmanial lesions of anaesthetized hamsters. Putatively infected flies were kept in mesh cages under laboratory controlled conditions $\left(20^{\circ} \mathrm{C}\right.$ and $\left.80 \% \mathrm{RH}\right)$.

Cages were inspected daily to change the sugarsoaked cotton wool and to remove dead or moribund insects. Between the 3rd and 9th day post- infection, the remaining flies were sacrificed and dissected in order to permit identification to species and detect infected individuals. Grades of infection were estimated following the criteria of Warburg et al. (1991).

\section{RESULTS}

A total of 13 isozymes were examined; seven of them showed pattens indistinguishable from two of the reference strains, i.e. R/BZ/62/M379 (Le. mexicana) and the MAN/VE/57/LL-1 (Le. pifanoi). However, both Samaniego (MAN/COL/85/1129 and Buenaventura (MAN/COL/89/1465) strains displayed different pattems for SOD (EC-1.15.1.1), G6PD (EC-1.1.1.49) and PGM (EC-2.7.5. 1). The two remaining systems (ACP and MPI) exhibited patterns consistent with the Le. amazonensis (VEC/ BR /67/PH8) reference strain, for both Colombian isolates (Fig. 2).

All sand flies collected in the study site were identified as $L u$. columbiana, a member of the $L u$. verrucarum species group (Young \& Duncan 1994). The numbers and percentages of specimens collected are discriminated by capture method in Table I. Overall sand fly activity was very low at that the time of the study (March), which coincided with the beginning of the rainy season. Although houses were similar in terms of environment, house 1 showed greater intradomestic activity of sand flies than the other two houses (Table I). Human bait was the most efficient method of collecting sand flies; a total of 155 females, 48 of these collected indoors and the remaining 107 in the peridomicile.

Despite the high peridomestic man-landing rate (11.8 sand flies/hour/man) recorded in the area, surprisingly, no sand flies were found in sticky traps inside the houses, and only four flies, two of them blood fed, were collected inside house 1 by this

\section{TABLE I}

Total numbers and percentages of Lutzomyia columbiana caught by different methods during three consecutive days in intradomicile (I) and peridomicile (P) areas in Samaniego (Nariño-Colombia)

\begin{tabular}{lccccccc}
\hline Sampling method & \multicolumn{9}{c}{ House } & & Total (\%) \\
\cline { 2 - 7 } & $\mathrm{I}$ & $\mathrm{P}$ & $\mathrm{I}$ & $\mathrm{P}$ & $\mathrm{I}$ & $\mathrm{P}$ \\
\hline Human bait & $25(12.7)$ & $93(47.3)$ & $23(11.7)$ & $12(6.0)$ & 0 & $2(1.0)$ & $155(78.7)$ \\
Sticky trap & $4(2.0)$ & 0 & 0 & 0 & 0 & 0 & $4(2.0)$ \\
Disney trap & 0 & $10(5.0)$ & 0 & 0 & 0 & 0 & $10(5.0)$ \\
Shannon trap & 0 & $\mathrm{NS}$ & 0 & $5(2.5)$ & $\mathrm{NS}$ & 0 & $5(2.5)$ \\
CDC trap & $16(8.1)$ & 0 & $4(2.0)$ & 0 & 0 & 0 & $20(10.1)$ \\
Aspiration from & 0 & 0 & 0 & 0 & 0 & $3(1.5)$ & $3(1.5)$ \\
diurnal resting sites & & & & & & & \\
\hline Total & $45(22.8)$ & $103(52.3)$ & $27(13.7)$ & $17(8.5)$ & 0 & $5(2.5)$ & $197(99.8)$ \\
\hline
\end{tabular}

NS: not sampled. 

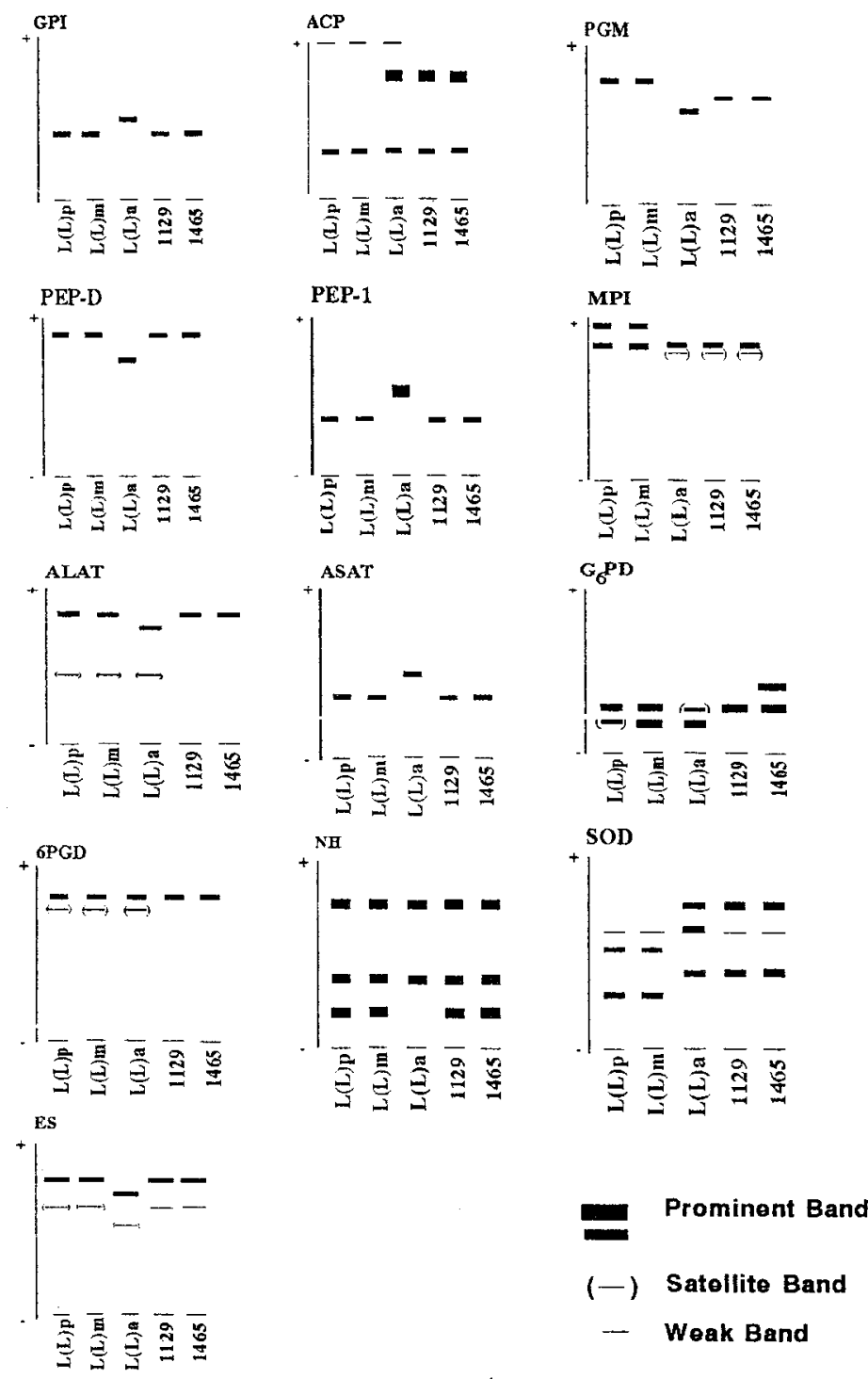

Fig. 2: isoenzyme patterns displayed by the WHO reference strains: L(L)p: Leishmania leishmania pifanoi (LL-1); L(L)m: Le. leishmania mexicana (M 379); L(L)a: Le. leishmania amazonensis (PH-8) and the Colombian strains 1129 and 1465. Thin bands and those within parentheses are secondary or satellite bands, which inconsistently appear in some stocks or strains.

\section{TABLE II}

Results of experimental infections of wild-caught Lutzomyia columbiana females using hamsters infected with Leishmania mexicana

\begin{tabular}{|c|c|c|c|c|c|c|}
\hline \multirow[t]{2}{*}{$\begin{array}{l}\text { No. infected/ } \\
\text { blood fed }\end{array}$} & \multirow[t]{2}{*}{$\begin{array}{c}\% \\
\text { infection }\end{array}$} & \multirow[t]{2}{*}{$\begin{array}{l}\text { Days post- } \\
\text { infection }\end{array}$} & \multicolumn{3}{|c|}{$\begin{array}{c}\text { Intensity of infection }^{a} \\
\text { n (\%) }\end{array}$} & \multirow[t]{2}{*}{$\begin{array}{l}\text { Time post-infection } \\
\text { of hamster (weeks) }\end{array}$} \\
\hline & & & 1 & 2 & 3 & \\
\hline \multirow[t]{2}{*}{$14 / 35$} & \multirow[t]{2}{*}{40} & $4-5$ & $2(14)$ & $7(50)$ & $5(36)$ & \multirow[t]{2}{*}{34} \\
\hline & & $6-7$ & 1(13) & $4(50)$ & $3(38)$ & \\
\hline \multirow[t]{2}{*}{$11 / 35$} & \multirow[t]{2}{*}{31} & $8-9$ & $1(33)$ & $1(33)$ & $1(33)$ & \multirow[t]{2}{*}{49} \\
\hline & & $3-4$ & $2(16)$ & $8(67)$ & $2(16)$ & \\
\hline $33 / 53$ & 58 & $5-6$ & - & $8(38)$ & $13(62)$ & 61 \\
\hline
\end{tabular}

$a: 1=<100$ parasites; $2=>100<1000$ parasites $3=>1000$ parasites. 
method. Analysis of their blood meals by Elisa indicated that the flies had fed on humans. Although no intradomestic activity was recorded in house 3 by any of the methods used, most $(80 \%)$ of the flies found in resting places were collected around this house.

All 10 sand fly specimens captured in Disney traps were attracted to guinea pigs, while no flies were collected in the traps baited with hamsters. Twenty Lu. columbiana were recovered from CDC traps hung outdoor of houses 1 and 2, whereas the trap set inside house 3 was always negative. The predominance of nulliparous females (63.6\%), suggested that most sand flies were seeking blood meals for the first time.

No promastigote infections were found in the digestive tract of $120 \mathrm{Lu}$. columbiana females from Samaniego. However, variable levels of infection were obtained experimentally. After three separate experiments a total of $123 \mathrm{Lu}$. columbiana were fed on hamster lesions. The infection rate ranged from $31-58 \%$ and appeared to increase with the time post-infection (p.i.) of the hamster (Table II). A semi-quantitative evaluation of infection intensity showed that $47.6 \%$ of sand fly infections were characterized by the presence of medium (grade 2 $=>100$ but $<1000$ parasites/gut) and $37 \%$ by high (grade $3=>1,000$ parasites/gut) numbers of promastigotes (Table II). In some flies the gut was almost entirely colonized by the parasite. No promastigote forms were seen attached to the pylorus or in the hindgut. Five days p.i., short-bodied forms with long flagella similar to infective promastigotes, were observed swimming freely in the proximity of the stomodeal valve and pharynx of flies. Between the 6th and 9th day p.i., an increasing number of promastigotes colonized the stomodeal valve.

\section{DISCUSSION}

Isozyme profile revealed that both Colombian (i.e.Samaniego and Buenaventura) strains of leishmania could be regarded as variants of $L e$. mexicana, at least for the 13 isozymes tested. Although Le. mexicana was previously recorded in Nariño Department (Corredor et al. 1990), it is unclear how this parasite had reached such a wide dispersion. The clinical histories of both patients in our study indicated that they had not moved (even temporally) to other places, therefore, infections appear to be authoctonous.

During the present short study, inclusion of a trapping method such as the sticky trap, that is not biased by light or human/animal odors, showed the predominance of $\mathrm{Lu}$. columbiana in the Samaniego area. This finding confirmed previous observations made more than 50 years ago by Rozeboom (1947), who noted that Lu. columbiana was the most abundant anthropophilic sand fly and likely vector of Bartonella bacilliformis during an outbreak of bartonellosis in Nariñlo. Entomological studies carried out 30 years later in the same area demonstrated that Lu. columbiana was the only sand fly species collected on human bait and in Shannon traps (pers. commun. Dr C Ferro, Instituto Nacional de Salud, Bogotá). Nevertheless, a long term and thorough sampling is required before excluding the presence of species such as Lu. flaviscutellata or Lu. olmeca, the known vector species of the Le. mexicana complex. The former species has proven to be difficult to detect in surveys of short duration (Ready et al. 1983).

The epidemiology of cutaneous leishmaniasis in Samaniego is poorly understood; hence, though preliminary, our field results may have significant epidemiological implications. For instance, the high rate of intradomicile contact between $L u$. columbiana and humans shows that this sand fly species has a clear endophagic behavior providing additional evidence for its previously recorded anthropophilia (Young \& Duncan 1994, Alexander et al. 1995). This behavioral aspect is particularly supported by the identification of human blood meals in wild caught flies. It is likely that the human-vector contact is higher during other periods of the year, since according to residents of Samaniego, the indoor biting nuisance is greatest during the dry season (June-July), and not at the time of year in which the present study was carried out (March). Since the highest proportion of human cases has been recorded in children (88.7\%), who usually go to bed early in the evening, and the leishmanial lesions are encountered on the faces of $73.3 \%$ of patients (Dr C Arroyo, Departmental Health Service, unpublished data), it can be inferred that transmission occurs indoors. This contrasts markedly with the transmission pattern of Chiclero's ulcer reported in Belize by Williams (1970), who concluded that leishmaniasis there was an occupational disease, with transmission occurring during the day in places where the chicle harvesters are in contact with Lu. olmeca, the known vector. However, a noteworthy similarity between the Le. mexicana foci in Central America and Samaniego is that, despite the ecological differences, in both cases the vectors prefer to bite the upper part of the body, particularly the head. Williams (1970) analyzed data of several studies carried out in Belize and Yucatan (Mexico) and found that $70 \%$ of lesions occurred on the head, especially in the ears. The author, however, could not explain this fact. In the case of Samaniego, we believe that the high predominance of ulcers on the patients' faces might 
be explained in tenns of both the endophagic activity of the vector and human behavior. Since noctumal temperatures fall to $2-5^{\circ} \mathrm{C}$, it is likely that the head is the only area exposed to sand flies, while the rest of the body is completely covered by blankets. A similar trend (i.e. very common facial lesions in young children), has been observed by Weigle et al. (1986) in other Leishmania foci on the Colombian Pacific coast.

Although no wild-caught mammals were used in Disney traps, collections made using guinea pigs as bait suggested that, in addition to humans, $L u$. columbiana could be attracted to rodents, and that this particular species could represent another blood source for peridomestic sand flies. Elsewhere, several species of rodents have been confined as reservoirs ofthe Le. mexicana species complex (Disney 1968, Williai-ns 1970, Lainson \& Shaw 1987).

Xenodiagnosis, a method that mimics natural infection because sand flies become infected by the intake of amastigotes from a mammal host, showed that promastigote development fulfilled the criteria of a typical suprapylarian Leishmania species, i.e. development restricted to the midgut and foregut of the sand fly vector (Lainson \& Shaw 1987). Since Le. mexicana is an adaptable species, capable of developing in a broad range of sand fly species (reviewed in Walters et al. 1987), we recognize that our results derived from experimental infections are not conclusive. Although the appearance of Le. mexicana metacyclic promastigotes by the 7th-9th day p.i. does not necessarily indicate a natural association between this parasite and $L u$. columbiana, it provides additional evidence to suggest that this sand fly species could be the vector. Moreover, $L u$. columbiana was the only species biting humans inside the houses where transmission most likely occurs.

Another important issue arising from these entomological studies in the CL focus of Samaniego is the absence of known Le. mexicana vectors. As new surveys in other leishmaniasis foci are carried out, it is probable that additional evidence on the vector role of other sand fly species, initially regarded as secondary vectors, will increase. Although we have no clear indication as to how the present epidemic of CL in Samaniego began, we speculate that among other factors, human migration might have played a paramount role. The first parasitologically confirmed cases were reported in La Mesa by Rodríguez et al. (1985) concomitant with the return of people, formerly dedicated to agriculture in the southwestern department of Putumayo. Since then, additional cases have been found in the same locality or neighboring areas, with the highest prevalence in the 0-4 year group (unpublished data from the Local Health Service, department of Nariño). In some endemic areas of Latin America, the Le. mexicana complex is not frequently reported in humans because the vectors, such as Lu. flaviscutellata, are not markedly anthropophilic (Desjeux 1992), and this could be the case for Putumayo where records of the disease exist. Thus, it is likely that a few immigrants and/ or their domestic animals (i.e. guinea pigs) became infected in Putumayo, and subsequently "imported" the disease to Samaniego. A second possible explanation is that humans could act as Leishmania reservoirs. A similar hypothesis was postulated to explain a CL outbreak due to Le. braziliensis in coffee-growing areas of Valle del Cauca (Montoya et al. 1990) where Lu. columbiana is also present.

Alternatively, it is also possible that an undetected Le. mexicana sylvatic cycle might have already existed in the Samaniego area. Regular indoor insecticide spraying by the Malaria Eradication Service could have precluded sand fly intradomestic activity until the control program was suspended. According to the inhabitants of the town, the increased intra- and peri-domestic biting activity of phlebotomines began at this point in time.

In summary, we conclude that $L u$. columbiana can be infected by Le. mexicana from Samaniego and other Leishmania foci in Colombia. Although no naturally infected flies were found during the present study this sand fly species displays both anthropophilic and zoophilic behavior, which together with other biological characteristics such as endophagy and ability to support full development of the parasite, constitute important traits of vector competency.

\section{ACKNOWLEDGEMENTS}

To Dr N Saravia for her constructive criticism during the writing of this manuscript. To Dr C Arroyo (Servicio de Salud de Nariño) and Mr G Londoño for their technical assistance.

\section{REFERENCES}

Alexander B, Usma MC, Cadena H, Quesada BL, Solarte Y, Roa W, Montoya J, Jaramillo C, Travi BL 1995. Phlebotomine sandflies associated with a focus of cutaneous leishmaniasis in Valle del Cauca, Colombia. Med Vet Entomol 9: 273-278.

Bemal G, Montalegre JE, Rangel ME, Sabogal TN 1989. Estudio sobre el Regimen de la Precipitación en Colombia. Instituto de Hidrología, Meteorología y Adecuación de Tierras (HIMAT). Subdirección de Estudios e Investigaciones División Hidrometeorología, Bogotá, Colombia, 186 pp.

Biagi FF, de Biagi AM de B, Beltrán HF 1965. Phlebotomus flaviscutellatus, transmisor natural de Leishmania mexicana. Prensa Méd Mex 30: 267-270.

Brumpt E, Brumpt L-Ch 1942. Etude epidemiologique concernant l'apparition de la verruga du Perou en 
Colombie. Ann Parasitol Hum Camp 19: 1-50.

Corredor A, Kreutzer RD, Tesh RB, Boshel J, Palau MT, Caceres E, Duque S, Pelaez D, Rodriguez G, Nichols S, Hemandez CA, Morales A, Young DG, Ferro C 1990. Distribution and etiology of leishmaniasis in Colombia. Am J Trop Med Hyg 42: 206- 214.

Desjeux P 1992. Human leishmaniases: epidemiology and public health aspects. Wld Hith Stat Quat 45: 267-275.

Disney RHL 1968. Observations on a zooleishmaniasis in British Honduras. J App Ecol 5: 1-59.

Grimaldi Jr G, Tesh RB, McMahon-Pratt D 1989. A review of the geographic distribution and epidemiology of leishmaniasis in the New World. Am J Trop Med Hyg 41: 687-725.

Hashiguchi Y, Gomez EAL, De Coronel VV, Mimori T, Kawabata M, Furuya M, Nonaka S, Takaoka H, Alexander JB, Quizhpe AM, Grimaldi G Jr, Kreutzer RD, Tesh RB 1991. Andean leishmaniasis in Ecuador caused by infection with Leishmania mexicana and L. major-like parasites. Am J Trop Med Hyg 44: 205- 217.

HIMAT 1993. Informe condiciones meteorológicas Estación de Tamaná-Nariño (1972- 1993). Unpublished document.

Lainson R, Shaw JJ 1987. Evolution, classification and geographic distribution, p.1-28. In W Peters, R Killick-Kendrick (eds), The Leishmaniases in Biology, and Medicine, Vol I, Academic Press, London.

Montoya J, Jaramillo C, Palma G, Gomez T, Segura I, Travi B 1990. Report of an epidemic outbreak of tegumentary leishmaniasis in a coffee-growing area of Colombia. Mem Inst Oswaldo Cruz 85: 119-121.

Porter H, Steurer FJ, Kreutzer RD 1987. Isolation of Leishmania mexicana mexicana from Lutzomyia ylephiletor in Guatemala. Trans R Soc Trop Med Hyg 81: 929-930.

Ready PD, Laison R, Shaw JJ 1983. Leishmaniasis in Brazil: XX. Prevalence of "enzootic rodent leishmaniasis" (Leishmania mexicana amazonensis) and apparent absence of "pian bois" (Le. braziliensis guyvaiiensis) in plantations of introduced tree species and in other non-climax forest in eastern Amazonia. Trans R Soc Trop Med Hyg 77: 775-785.

Rodríguez G, Corredor A, Cáceres E, Cassiano G, Arroyo C, Palaú M, Boshell J 1985. Leishmaniasis difusa. Biomédica 5: 95-111.

Rozeboom LE 1947. The identity of the Phlebotomus associated with bartonellosis in Colombia. Ann Entomol Soc Am 40: 705-714.

Saravia NG, Holguin AF, McMahon-Pratt D, D’Alessandro A 1985. Mucocutaneous leishmaniasis in Colombia: Leishmania braziliensis subspecies diversity. Am J Trop Med Hyg 34: 714-720.

Service MW 1993. Mosquito Ecology: Field Sampling Methods, 2nd ed., Elsevier Applied Science Press, London \& New York, 988 pp.

Voller A, Bidwell DE \& Barttlet A 1980. Enzyme linked inununosorbent assay, p. 6-21. In N Rose, H Friedman (eds), Manual of Clinical Immunology, American Society of Microbiology, Washington.

Young DG, Duncan MA 1994. Guide to the identification and geographic distribution of Lutzomyia sand flies in Mexico, West Indies, Central and South America (Diptera: Psychodidae). Mem Am Entomol Inst 54: 1-881.

Warburg A, Montoya-Lenna J, Jaramillo C, Cruz-Ruiz AL, Ostrovska K 1991. Leishmaniasis vector potential of Lutzomyia spp. in Colombian coffee plantations. Med Vet Entomol 5: 9-16.

Walters LL, Modi GD, Tesh RB, Burrage T 1987. Hostparasite relationship of Leishmania mexicana mexicana and Lutzomyia abonnenci (Diptera: Psychodidae). Am J Trop Med Hyg 36: 294-314.

Weigle, KA, Saravia NG, de Davalos M, Moreno LH, D’Alessandro A 1986. Leishmania braziliensis from the Pacific Coast region of Colombia: foci of transmission, clinical spectrum and isoenzyme phenotypes. Am J Trop Med Hyg 35: 206-214.

Williams P 1970. Phlebotomine sandfiies and leishmaniasis in British Honduras, (Belize). Trans R Soc Trap Med Hyg 64: 317-364. 